\title{
Cutting through the Noise: How to Shape Public Perception, Frame the Debate and Effectively Engage Your Audience in the Digital Age
}

\author{
Julius van de Laar \\ Strategic Campaigns \& Communication, Germany \\ julius@juliusvandelaar.com
}

Successful political campaigns have mastered the tactics and strategies used to effectively present an argument, manage and respond with authority during crisis, influence the debate and shape public perception.

Yet, in todays 24/7 media environment it has become more difficult than ever to set an agenda, frame an issue or engage an audience.

Four years ago, Barack Obama set a new standard for campaigning by changing the way new media was used to build an aspirational brand, engage and empower supporters, raise money and turn out voters. As the 2012 presidential race unfolds, the campaigns are stepping up their game. And in this cycle, they are embracing digital media more than ever.

However, its not only the Presidents campaign and his opponents who are faced with the challenge to create a narrative and frame the public debate. Organizations in the private sector often deal with the similar complex issues as they struggle to deliver tailored messages to target their audience, regardless of whether its costumers, investors, media, the general public or even potential employees.

From storytelling to big data lifestyle targeting: Julius van de Laar will provide a first hand account on how todays most effective campaigns leverage battle tested strategies combined with new media tools to create a persuasive narrative and how they translate into actionable strategies for the corporate context. 